\title{
Morphometric analysis of the uncinate processes of the cervical vertebrae
}

\author{
N. Kocabiyik ${ }^{1}$, N. Ercikti ${ }^{1}$, S. Tunali ${ }^{2}$ \\ ${ }^{1}$ Department of Anatomy, Gulhane Medical Faculty, Health Sciences University, Ankara, Turkey \\ ${ }^{2}$ TOBB University of Economics and Technology Faculty of Medicine, Sogutozu, Ankara, Turkey
}

[Received: 26 December 2016; Accepted: 21 January 2017]

\begin{abstract}
Background: Uncinate processes (UPS) are distinct features unique to cervical vertebrae. They are consistently found on posterolateral aspect of the superior end plate of $3^{\text {rd }}$ to $7^{\text {th }}$ cervical vertebrae. In this study, we investigated the morphology of the UPs with a particular emphasis on the regional anatomy and clinical significance. Materials and methods: The study included 63 vertebrae. The width, height and length of UPS were measured with a digital calliper. We also assessed inclination angle of UP relative to sagittal plane, angle between medial surface of UP and superior surface of vertebra, angle between long axis of the UP and frontal plane, angle between long axis of UP and sagittal plane.

Results: Average width of the UPs ranged from $4.25 \mathrm{~mm}$ at C3 to $6.33 \mathrm{~mm}$ at T1; average height ranged from $4.88 \mathrm{~mm}$ at $T 1$ to $7.54 \mathrm{~mm}$ at C4; and average length ranged from $6.88 \mathrm{~mm}$ at $T 1$ to $11.46 \mathrm{~mm}$ at C4. We measured the inclination angle of UP relative to sagittal plane, and found it to be relatively constant with $T 1$ having the largest value. The average angle was $41.39^{\circ}$, and the range was $17^{\circ}$ to $85^{\circ}$. The angle between the long axis of the UP and the sagittal plane was increasing significantly from C5 to T1. The average angle was $20.74^{\circ}$ and the range was $6^{\circ}$ to $65^{\circ}$. Conclusions: Anatomy of UPs is significant for surgeon who operates on the cervical spine. Hopefully, the information presented herein would decrease complications during surgical approaches to the cervical spine. (Folia Morphol 2017; 76, 3: 440-445)
\end{abstract}

Key words: uncinate process, uncovertebral joint, Luschka joint, cervical spine

\section{INTRODUCTION}

In 1834, Rathke [see 3] has defined the uncinate process (UP) as a bony protuberance that extends from posterior margin of vertebral body. In 1858, Von Luschka [see 25] introduced the description of uncovertebral joint between the UP and vertebra.

The localisation of UP on vertebral column anteriorly extends up to the third cervical vertebra, and posteriorly down to the second thoracic vertebra [30]. They are mostly found between segments C3 to C7 $[1,4,29]$. UPs are further defined as bony protuber- ances, protuberentia, prominentia, bridges or lips extending from lateral or posterolateral segments of cervical vertebral bodies $[1,4,7,8,11,12,14,18$, $31,32]$. They have an anterior slope, an apex and a posterior slope besides a medial articular surface [4]. In addition, UPs deliver a concave appearance to the upper tips of vertebral bodies on the coronal plane $[14,28]$. They have a more posterior location on lower vertebral segments [30].

The purpose of this study was to define the morphology of UPs in Turkish population with an 


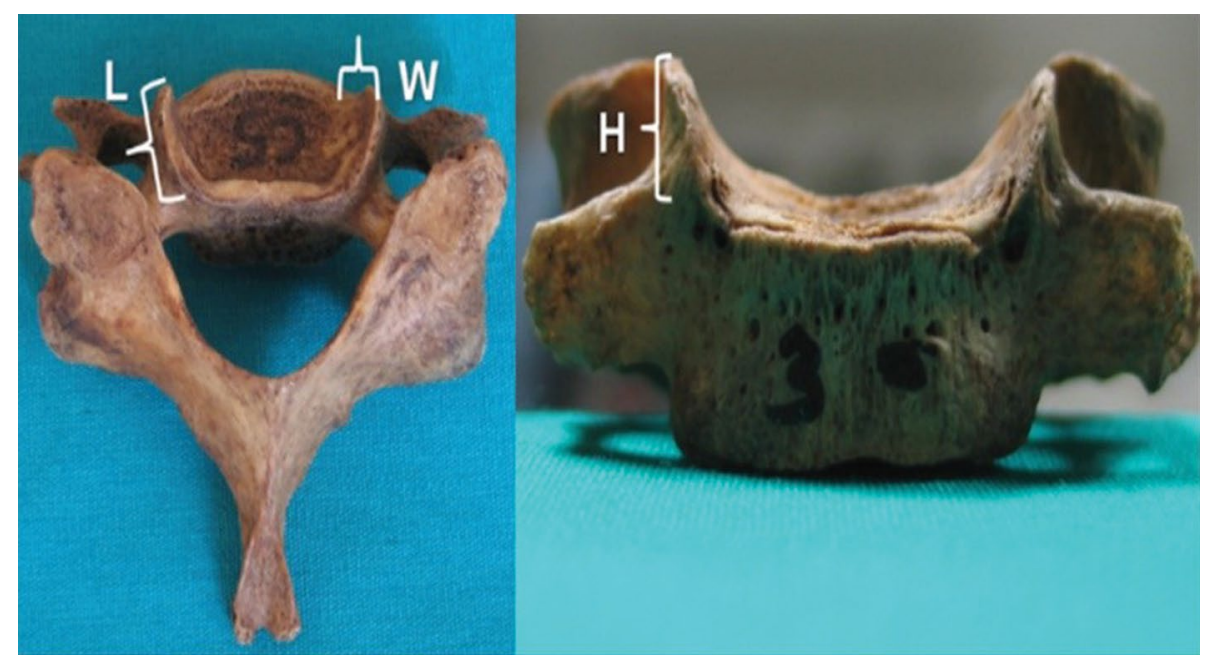

Figure 1. The width $(W)$, height $(H)$ and length $(L)$ of uncinate processes.

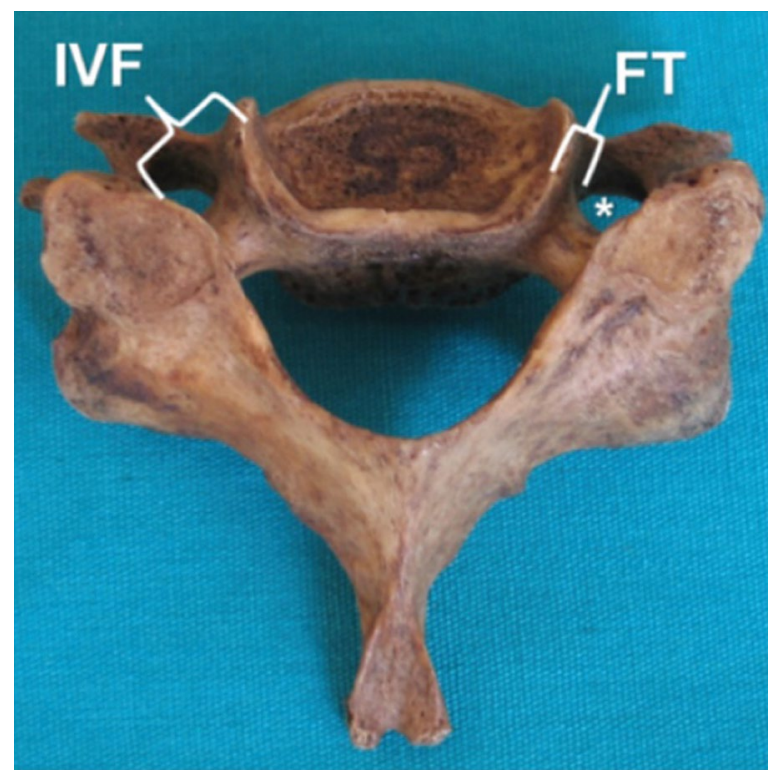

Figure 2. The uncinate process is found on the lateral margin of the superior endplate in close proximity to the intervertebral foramen (IVF) and foramen transversarium (FT); ${ }^{*}$ foramen transversarium.

emphasis on their relevance to the regional anatomy, and their clinical significance.

\section{MATERIALS AND METHODS}

A total of 75 vertebrae were used in this study. Of them, 20 were $C 3$ vertebrae, 20 were $C 4,9$ were $C 5$, 6 were C 6,8 were C7, and 12 were T1. Adult vertebrae present in the anatomy laboratory, of ages between 65 and 75 years were used. No gender classification was made. Twelve vertebrae ( 4 from C3, 7 from C4 and 1 from
C5) were excluded due to destruction probably due to osteoporosis or bony degeneration. Hence, 63 vertebrae with intact UPs were involved in measurements. The width, height and length of UPs were measured (Fig. 1).

Furthermore, the distance of the apex of the UP to intervertebral foramen (IVF) and foramen transversarium (FT) was studied (Fig. 2). We also assessed inclination angle of UP relative to sagittal plane (B), angle between medial surface of UP and superior surface of vertebra $(A+B)$, angle between long axis of UP and sagittal plane $(C)$, angle between long axis of the UP and frontal plane (C+D) (Fig. 3). All measurements were made using an electronic digital calliper accurate to $0.1 \mathrm{~mm}$. Angles were measured with a goniometer.

\section{Statistical analysis}

Statistical analysis was done with SPSS (Chi., IL, USA) software. Descriptive statistics were presented as mean \pm standard deviation. Pearson correlation analysis was performed to determine the linear association between morphometric parameters in C3-T1 vertebrae; $p<0.05$ was accepted as statistically significant.

\section{RESULTS}

Foramina transversaria of vertebrae C3, C4, C5 and $\mathrm{C} 6$ had bifid spinous process while FT of vertebra C7 had smaller, non-bifid and obvious spinous processes. Vertebra T1 had no FT, and joint surfaces for ribs on their bodies were notable. The width, height and length of UPs on vertebrae C3-T1, as well as the distances of their apex to the IVF and the FT are presented in Table 1. 


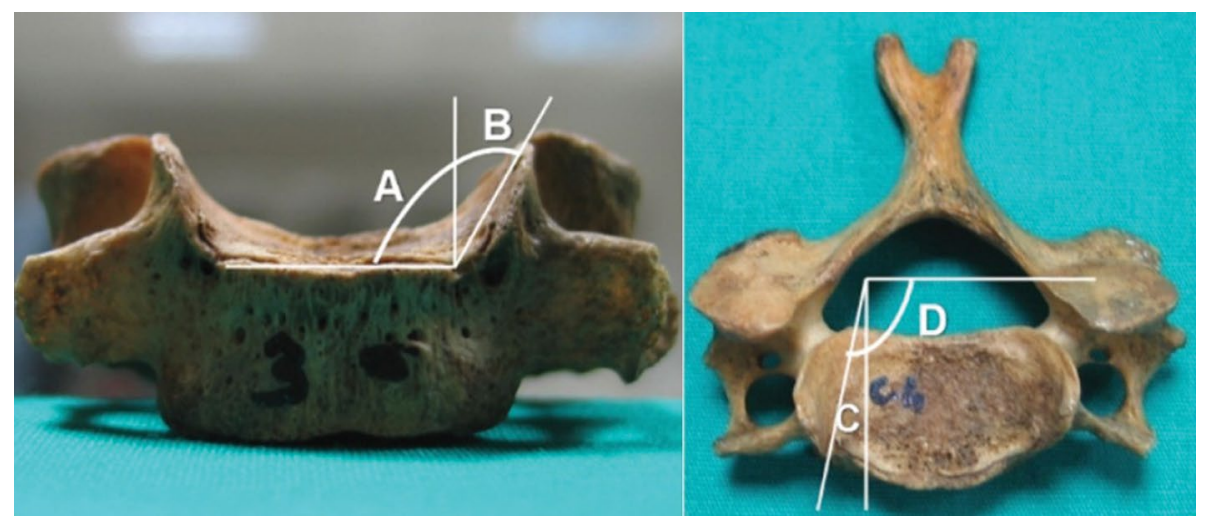

Figure 3. Inclination angle of uncinate process relative to sagittal plane (B), angle between medial surface of uncinate process and superior surface of vertebra $(A+B)$, angle between long axis of uncinate process and sagittal plane $(C)$, angle between long axis of the uncinate process and frontal plane $(C+D)$.

Morphometric measurements of vertebrae C3-T1 reveal an average $(r=0.536)$ positive correlation in the width of UPs; however, a negative correlation in height $(r=-244)$ and length $(r=-432)$. While an increasing pattern is observed from C3 to $\mathrm{T} 1$, this is exactly opposite in height and length except for a few exceptions. An assessment of the height and length trend reveals that such pattern is reversed particularly in vertebra $\mathrm{C} 4$ and $\mathrm{C} 5$, and occasionally in vertebra $\mathrm{C} 6$.

The inclination angle of UP relative to sagittal plane (B) was relatively constant, with $\mathrm{T} 1$ having the largest value. The average angle $B$ was $41.39^{\circ}$, and the range was $17^{\circ}$ to $85^{\circ}$. The angle between the long axis of the UP and the sagittal plane (C) was increasing significantly from $\mathrm{C} 5$ to $\mathrm{T} 1$. The average angle $\mathrm{C}$ was $20.74^{\circ}$, and the range was $6^{\circ}$ to $65^{\circ}$. An overall evaluation of these angular measurements reveals that angle $C$ has the highest correlation within the range of vertebrae from C3 to T1 $\left(10.00 \pm 1.79^{\circ} ; r=0.794, p<0.001\right.$, on the right, and $9.56 \pm 1.52^{\circ} ; r=0.750, p<0.001$, on the left). Similarly, the angle $C+D$ displayed a high correlation within the same range at an angle of $100.00 \pm 1.79^{\circ}(r=0.795$, $p<0.001)$ on the right side, and $99.56 \pm 1.55^{\circ}$ $(r=0.759, p<0.001)$ on the left side.

\section{DISCUSSION}

The UP is a phylogenetic residue of the costovertebral joint in reptiles and birds [1]. Tubbs et al. [29] found that the height of the UP was 5-6 $\mathrm{mm}$ at the C4-6 levels, making the anterolateral window for decompression of the neural foramen determinable by the height and width of the UP, and this is comparable to the findings of Lu et al. [13]. These authors also found that the UPs were significantly taller at C4-C6 levels $[13,29]$. In our cases, highest length was found in UPs of vertebrae C4-C6.

In addition, height of UPs was reported in 10 studies, indicating an increasing pattern from $\mathrm{C} 3$ to lower cervicals. This pattern was not observed in the studies of Civelek et al. [6] and Pait et al. [18], and UPs of C5 were found to be shorter compared to those of the adjacent vertebra C4 and C6. Moreover, 4 of 10 studies revealed shorter UPs of C7 compared to those of the adjacent C6 $[6,13,15,23]$. The length of UPs revealed a range of minimum $2 \mathrm{~mm}$ at $\mathrm{C} 7$ to maximum $10.5 \mathrm{~mm}$ at $\mathrm{C} 6$ [22, 29]. In our cases, highest UP was observed at vertebra C4 (7.54 $\pm 1.39 \mathrm{~mm}$ on the right side and $7.35 \pm 1.17$ $\mathrm{mm}$ on the left side) followed by the vertebra C6 (7.42 \pm $\pm 1.34 \mathrm{~mm}$ on the right side and $7.04 \pm 1.25 \mathrm{~mm}$ on the left side). Indeed, a declining pattern of height after the vertebra $\mathrm{C} 6$ is not surprising, because no UP is observed after vertebra $\mathrm{C} 7$ and $\mathrm{T} 1$. In vertebra T1, UPs height was found to be the shortest compared to all cervical vertebra $(5.53 \pm 0.85 \mathrm{~mm}$ on the right side and $4.88 \pm$ $\pm 0.79 \mathrm{~mm}$ on the left side). Lower values at $\mathrm{T} 1$ confirm our hypothesis above. It should further be added that, such a variation in the height is probably due to different types of samples ranging from fresh cadavers to dry vertebrae underlying the morphometric data reported in this study.

Kotani et al. [11] and Snyder et al. [26] showed that the posterior segment of UPs provide more stability, compared to the anterior segment. Authors believed this finding was due to the wider and longer morphology of the posterior segment of UP compared to its anterior segment. The uncovertebral articulation was found to contribute in excess of $60 \%$ of the stability of the spinal motion segment in extension at C3-C4 [11]. 


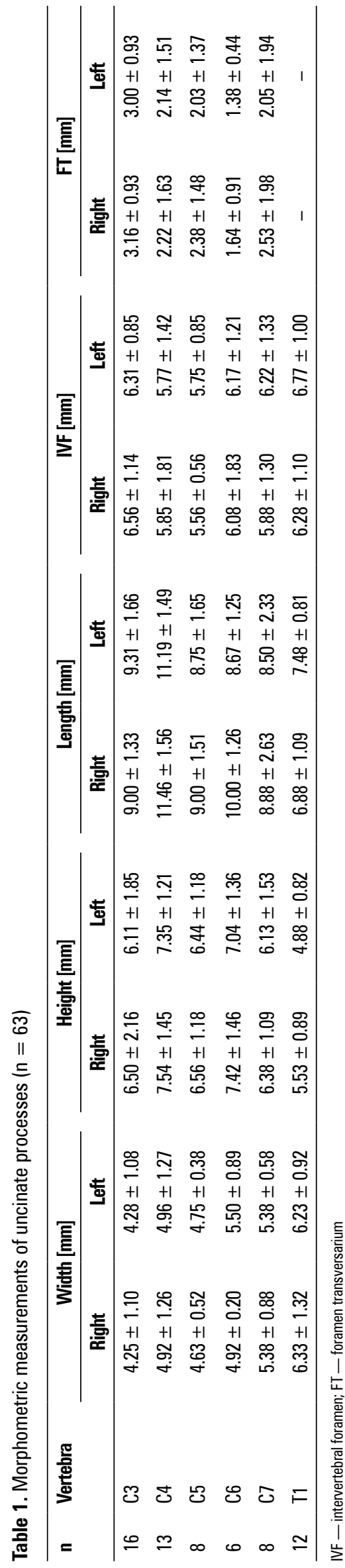

In the literature, it is reported that the width of UPs shows an increasing pattern from $\mathrm{C} 3$ to $\mathrm{C} 7$, similar to the height trend. Average widths are reported to be in the range of $4.6 \mathrm{~mm}$ at $\mathrm{C} 3$ to $7.4 \mathrm{~mm}$ at $\mathrm{C} 76,13]$. Next, two of six studies report a lower average width of UPs at C5 compared to $\mathrm{C} 4$, and one study reports a wider UP at $C 5$ compared to $C 6[6,13,18]$. Yilmazlar et al. [32] attributed the increased width of the UP at $\mathrm{C} 5$ to spondylosis secondary to the increased cervical segmental motion at this level. In our cases, widest UPs were found at vertebrae C7 (5.38 $\pm 0.82 \mathrm{~mm}$ on the right side and $5.38 \pm 0.54 \mathrm{~mm}$ on the left side) and at vertebrae T1 $(6.33 \pm 1.26 \mathrm{~mm}$ on the right side and $6.23 \pm 0.88 \mathrm{~mm}$ on the left side). In our study, average width of UPs at vertebrae C4 (4.92 $\pm 1.21 \mathrm{~mm}$ on the right side, and $4.96 \pm 1.22 \mathrm{~mm}$ on the left side) was found to be exceeding that of the adjacent vertebrae $\mathrm{C} 3$ and $\mathrm{C5}$.

In the literature, also the anterior-posterior lengths of UPs are assessed, revealing an overall pattern of increase towards $\mathrm{C} 7$ from $\mathrm{C} 3$. Average lengths are reported to be in the range of $6.0 \mathrm{~mm}$ at $\mathrm{C} 3$ to $13.0 \mathrm{~mm}$ at C7 [4]. However, 2 of 5 studies report longer UPs of C7 compared to those of $C 6[4,19]$. In our cases, measured lengths of $\mathrm{C} 7$ and T1 UPs were lower compared to that of vertebra C6. Indeed, length and height of UPs display a gradually decreasing pattern towards lower cervicals, namely after C6. This is quite expectable, as these protuberances are not observed after $\mathrm{T} 1$. Therefore, they are very obvious throughout the $\mathrm{C} 3-\mathrm{C} 6$ range. After $\mathrm{C} 6$, we see a decline in the morphometric values of UPs due to relative downsizing.

Tubbs et al. [29] classified the UP with regard to the degree of impingement of the ipsilateral IVF. No typology was performed in our study. However, the proximity of uncinate process' apex to IVF and to FT was studied. In our study, smallest distance between uncinate process' upper margin and IVF was observed at C5. On the other hand, distance of uncinate process' upper margin to FT was observed to be lowest at C5, and highest in C3.

Intervertebral foramen at the cervical spine forms an angle of $45^{\circ}$ with rather the coronal plane, and extends forward from the vertebral channel $[9,20]$. Anteromedial margin of IVF is constructed with the posterolateral segment of the uncovertebral joint $[5,11$, $14,21,24,27]$. Posterior segment of the uncovertebral joint is associated with the front branches of nerve roots, and the lateral segment of the spinal cord [9]. As the nerve roots pass through the IVF they are found in the lower third of the space with the apex of the UP being above each root $[9,20]$. The more anterior portion of 
the uncovertebral joint has its lateral surface being in proximity to the vertebral artery and its accompanying venous plexus [33]. The distance between the medial margin of the FT - in which the vertebral artery and veins travel - and the UP increases from C3 to C7 [9, $10,17,31]$. The segment of the vertebral artery that is related to the UP is the portion located between the transverse processes of adjacent vertebrae. Nourbakhsh et al. [16] demonstrated that these segments demonstrate tortuosity in $13.4 \%$ of all intertransverse segments. Tortuosity was greatest at the third to fifth intertransverse spaces and was more likely to be present in segments demonstrating degeneration.

Panjabi et al. [19] measured the slope angle of UPs with the sagittal plane and found a relatively fixed angle peaking at C7. Average angle found was $40.3^{\circ}$ [19]. In our study, this angle was found to be highest between cervical vertebrae, with $46.13 \pm 15.6^{\circ}$ on the right side and $47.25 \pm 15.64^{\circ}$ on the left side. However, an increase is noteworthy at $\mathrm{C} 4$ on the right side $\left(48.08 \pm 11.69^{\circ}\right)$. Among all vertebrae with UP, maximum angle was $52.17 \pm 8.02^{\circ}$ on the right side and $47.67 \pm 5.44^{\circ}$ on the left side. Also in the literature, the angle between the long axis of UPs and the frontal plane was analysed, revealing a significant increase from $C 5$ to $C 7$, averaging $91.02^{\circ}$. In our study, such angle measured was highest between cervical vertebrae, with $114.63 \pm 5.45^{\circ}$ on the right side and $111.00 \pm 3.81^{\circ}$ on the left side in average. Again in our study, highest value was found in $\mathrm{T} 1$ as $138.75 \pm$ $\pm 7.84^{\circ}$ on the right side and $135.33 \pm 10.53^{\circ}$ on the left side. Saringer et al. [23] measured the angle between the long axis of UPs and the sagittal plane, and similarly reported an increasing pattern towards lower cervicals. Average angle measured was reported as $5.06^{\circ}$. And also in our study, there is an increase from C3 to $\mathrm{T} 1$.

Ugur et al. [31] and Bozbuga et al. [2] measured the angle between the medial surface of UPs and the upper surface of vertebra, and reported a greatly varying value in the $90-162^{\circ}$ range. In our study, this angle was calculated as $123.66 \pm 8.11^{\circ}$ on the right side and $123.38 \pm 7.30^{\circ}$ on the left side in $\mathrm{C} 3$, and $135.5 \pm 14.05^{\circ}$ on the right side and $137.25 \pm 15.64^{\circ}$ in the left side in $\mathrm{C7}$. A positive, statistically significant correlation was found between the vertebra sequence (from C3 to T1) and angle $C$ (the angle between long axis of UP and sagittal plane) $(r=0.794, p<0.001)$.

\section{CONCLUSIONS}

As a conclusion; UPs are defined as critical structures in head and neck movements. Their interaction with the inferior side of vertebrae makes up the uncovertebral joints. These uncovertebral joints are in a lifetime development from a rudimentary joint up to a mature joint, and eventually degenerate. In some cases, these degraded joints become clinically visible due to the compressive effect of uncinate osteophytes. These compressive effects culminate in nerve root compression in IVF besides vertebral artery compression as osteophytes hand down onto the lateral. Due to this condition, pain, paraesthesia, reflex decay, muscle weakness and even symptomatic vertebrobasilar failures may occur. Besides being an injury site in patients with severe head and neck trauma, UPs and uncovertebral joints were mistaken for torticollis in acute cases in young people. Despite being often neglected due to their relatively small size; uncovertebral joints have major contributions to the stability of the cervical spine. In our study, also the UP of vertebra T1 was studied in addition to the literature.

While a positive correlation was observed in the width of these protuberances downwardly towards lower cervicals, a declining pattern, as suggested by some authors, was found in height and length after C6. We hope that, supporting morphometric studies with radiologic efforts to exhaustively study UPs in a wider sample population would serve as a guide for neurosurgeons conducting uncinectomy and uncoforaminotomy.

\section{REFERENCES}

1. Bland JH, Boushey DR. Anatomy and physiology of the cervical spine. Semin Arthritis Rheum. 1990; 20(1): 1-20, indexed in Pubmed: 2218549.

2. Bozbuğa M, Oztürk A, Ari Z, et al. Surgical anatomic evaluation of cervical uncinate process for ventral and ventrolateral subaxial decompression. Okajimas Folia Anat Jpn. 1999; 76(4): 193-196, indexed in Pubmed: 10565202.

3. Brismée JM, Sizer PS, Dedrick GS, et al. Immunohistochemical and histological study of human uncovertebral joints: a preliminary investigation. Spine. 2009; 34(12): 1257-1263, doi: 10.1097/BRS.0b013e31819b2b5d, indexed in Pubmed: 19455000.

4. Browne KM. The anatomy, spatial relationships, and role of uncovertebral articulations as the source of posterolateral cervical cartilage sequestrations. J Neurosurg Spine. 2010; 12(3): 270-274, doi: 10.3171/2009.10.SPINE09367, indexed in Pubmed: 20192626.

5. Cave AJ, Griffiths JD, Whiteley MM. Osteo-arthritis deformans of the Luschka jounts. Lancet. 1955; 268(6856): 176-179, indexed in Pubmed:13234316.

6. Civelek E, Kiris T, Hepgul K, et al. Anterolateral approach to the cervical spine: major anatomical structures and landmarks. Technical note. J Neurosurg Spine. 2007; 7(6): 669-678, doi: 10.3171/SPI-07/12/669, indexed in Pubmed: 18074695.

7. Clausen JD, Goel VK, Traynelis VC, et al. Uncinate processes and Luschka joints influence the biomechanics of the cervi- 
cal spine: quantification using a finite element model of the C5-C6 segment. J Orthop Res. 1997; 15(3): 342-347, doi: 10.1002/jor.1100150305, indexed in Pubmed: 9246079.

8. Del Sasso L, Mondini A, Brambilla S, et al. Operative treatment of cervicobrachialgia and vertigo due to uncovertebral joint arthritis. Ital J Orthop Traumatol. 1991; 17(4): 498-504, indexed in Pubmed: 1816155.

9. Ebraheim NA, Lu J, Biyani A, et al. Anatomic considerations for uncovertebral involvement in cervical spondylosis. Clin Orthop Relat Res. 1997(334): 200-206, indexed in Pubmed: 9005914.

10. Ebraheim NA, Lu J, Brown JA, et al. Vulnerability of vertebral artery in anterolateral decompression for cervical spondylosis. Clin Orthop Relat Res. 1996(322): 146-151, indexed in Pubmed: 8542690

11. Kotani Y, McNulty PS, Abumi K, et al. The role of anteromedial foraminotomy and the uncovertebral joints in the stability of the cervical spine. A biomechanical study. Spine. 1998; 23(14): 1559-1565, indexed in Pubmed: 9682312.

12. Lee JY, Löhr M, Impekoven $P$, et al. Small keyhole transuncal foraminotomy for unilateral cervical radiculopathy. Acta Neurochir. 2006; 148(9): 951-958, doi: 10.1007/s00701006-0812-7, indexed in Pubmed: 16804642.

13. Lu J, Ebraheim NA, Haman SP, et al. Cervical uncinate process: an anatomic study for anterior decompression of the cervical spine. Surg Radiol Anat. 1998; 20(4): 249-252, indexed in Pubmed: 9787390.

14. Lyon E. Uncovertebral osteophytes and osteochondrosis of the cervical spine. J Bone Joint Surg Am. 1945; 27: 248-253.

15. Milne N. The role of zygapophysial joint orientation and uncinate processes in controlling motion in the cervical spine. J Anat. 1991; 178: 189-201, indexed in Pubmed: 1810926.

16. Nourbakhsh A, Yang J, Gallagher S, et al. A safe approach to explore/identify the $\mathrm{V}(2)$ segment of the vertebral artery during anterior approaches to cervical spine and/or arterial repairs: anatomical study. J Neurosurg Spine. 2010; 12(1): 25-32, doi: 10.3171/2009.7.SPINE08504, indexed in Pubmed:20043760.

17. Oh SH, Perin NI, Cooper PR. Quantitative three-dimensional anatomy of the subaxial cervical spine: implication for anterior spinal surgery. Neurosurgery. 1996; 38(6): 1139-1144, indexed in Pubmed: 8727144.

18. Pait TG, Killefer JA, Arnautovic KI. Surgical anatomy of the anterior cervical spine: the disc space, vertebral artery, and associated bony structures. Neurosurgery. 1996; 39(4): 769-776, indexed in Pubmed: 8880772.

19. Panjabi MM, Duranceau J, Goel V, et al. Cervical human vertebrae. Quantitative three-dimensional anatomy of the middle and lower regions. Spine. 1991; 16(8): 861-869, indexed in Pubmed: 1948369.

20. Pesch HJ, Bischoff W, Becker T, et al. On the pathogenesis of spondylosis deformans and arthrosis uncovertebralis: comparative form-analytical radiological and statistical studies on lumbar and cervical vertebral bodies. Arch Orthop Trauma
Surg. 1984; 103(3): 201-211, indexed in Pubmed:6497609.

21. Raynor RB. Anterior or posterior approach to the cervical spine: An anatomical and radiographic evaluation and comparison. Neurosurgery. 1983; 12: 7-13.

22. Russo VM, Graziano F, Peris-Celda M, et al. The V(2) segment of the vertebral artery: anatomical considerations and surgical implications. J Neurosurg Spine. 2011; 15(6): 610-619, doi: 10.3171/2011.7.SPINE1132, indexed in Pubmed: 21905775.

23. Saringer WF, Reddy B, Nöbauer-Huhmann I, et al. Endoscopic anterior cervical foraminotomy for unilateral radiculopathy: anatomical morphometric analysis and preliminary clinical experience. J Neurosurg. 2003; 98(2 Suppl): 171-180, indexed in Pubmed: 12650402.

24. Shen FH, Samartzis D, Khanna N, et al. Comparison of clinical and radiographic outcome in instrumented anterior cervical discectomy and fusion with or without direct uncovertebral joint decompression. Spine J. 2004; 4(6): 629-635, doi: 10.1016/j.spinee.2004.04.009, indexed in Pubmed: 15541694.

25. Silberstein CE. The evolution of degenerative changes in the cervical spine and an investigation into the "joints of luschka". Clin Orthop Relat Res. 1965; 40: 184-204, indexed in Pubmed: 14304709.

26. Snyder JT, Tzermiadianos MN, Ghanayem AJ, et al. Effect of uncovertebral joint excision on the motion response of the cervical spine after total disc replacement. Spine. 2007; 32(26): 2965-2969, doi: 10.1097/BRS.0b013e31815cd482, indexed in Pubmed: 18091488.

27. Tanaka N, Fujimoto $\mathrm{Y}, \mathrm{An} \mathrm{HS}$, et al. The anatomic relation among the nerve roots, intervertebral foramina, and intervertebral discs of the cervical spine. Spine (Phila Pa 1976). 2000; 25(3): 286-291, indexed in Pubmed: 10703098.

28. Taylor J, Twomey L, Levander B. Contrasts between cervical and lumbar motion segments. Crit Rev Phys Rehabil Med. 2000; 12: 345-371.

29. Tubbs RS, Rompala OJ, Verma K, et al. Analysis of the uncinate processes of the cervical spine: an anatomical study. J Neurosurg Spine. 2012; 16(4): 402-407, doi: 10.3171/2011.12. SPINE11541, indexed in Pubmed: 22264177.

30. Tulsi RS, Perrett LV. The anatomy and radiology of the cervical vertebrae and the tortuous vertebral artery. Aust Radiol. 1975; 19(3): 258-264, indexed in Pubmed: 1212130.

31. Uğur HC, Uz A, Attar A, et al. Anatomical projection of the cervical uncinate process in ventral, ventrolateral, and posterior decompressive surgery. J Neurosurg. 2000; 93(2 Suppl): 248-251, indexed in Pubmed: 11012055.

32. Yilmazlar S, Ikiz I, Kocaeli $\mathrm{H}$, et al. Details of fibroligamentous structures in the cervical unco-vertebral region: an obscure corner. Surg Radiol Anat. 2003; 25(1): 50-53, doi: 10.1007/ s00276-002-0087-5, indexed in Pubmed: 12819950.

33. Yilmazlar S, Kocaeli $H, U z A$, et al. Clinical importance of ligamentous and osseous structures in the cervical uncovertebral foraminal region. Clin Anat. 2003; 16(5): 404-410, doi: 10.1002/ca.10158, indexed in Pubmed: 12903062. 